ARTES, AmÉlia; unBEHAuM, SANDrA; SilVÉRIO, VAlter (orgs.). AÇÕES AFIRMATIVAS NO BRASIL: EXPERIÊNCIAS BEM-SUCEDIDAS DE ACES-

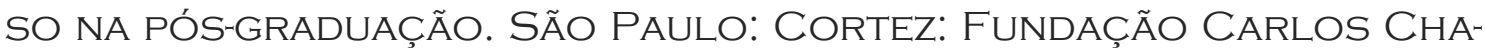
GAS, 2016.288 P, V. 1.

\title{
AÇÕES AFIRMATIVAS EM PERSPECTIVA
}

\section{MARCOS ANTONIO BATISTA DA SILVA*}

O livro Ações Afirmativas no Brasil: experiência bem-sucedida de acesso na pósgraduação divulga resultados, traz reflexões críticas, e retrata avaliação dos cursos de formação pré-acadêmicas de doze das quinze universidades públicas selecionadas pelo edital do Programa Equidade da Fundação Carlos Chagas (FCC), São Paulo, e apoio da Fundação Ford. A FCC, em parceria com a Fundação Ford, abriu em 2011, inscrições para universidades públicas e particulares, que já dispunham de experiências de ação afirmativa na graduação, para que implementassem cursos de formação visando à preparação de potenciais candidatos aos processos seletivos de Programas de Pósgraduação (PPG) de universidades brasileiras. Os alunos deveriam receber formação que os capacitasse para prestar seleção em qualquer PPG brasileiro e nas diversas áreas de conhecimento.

O concurso ${ }^{1}$ previa duas modalidades de propostas: consórcio, quando duas ou mais universidades se associam para apresentar uma única proposta. Para a modalidade consórcio foram previstas três dotações; individual, quando a proposta é apresentada por uma única universidade. Para a modalidade individual foram previstas dez dotações.

O projeto do Programa Equidade previa também uma avaliação externa com o objetivo de analisar o impacto da implementação da experiência de formação préacadêmica em dois planos: o processo de implementação na instituição, com especial atenção à sua integração institucional; follow-up dos egressos, sua inserção ou não em

\footnotetext{
* Doutor em Psicologia Social pela Pontifícia Universidade Católica de São Paulo (PUC-SP). Bolsista PNPD/CAPES em Psicologia Educacional no Programa de Pós-Graduação do Centro Universitário Fieo (Unifieo), Osasco, SP. E-mail: marcos.psico@yahoo.com.br

${ }^{1}$ http://www.uneb.br/files/2011/02/F. FORD-EQUIDADEcaderno_concurso_1.pdf.
} 
Programas de Pós-graduação (PPG).

A FCC é uma entidade fundacional de direito privado, sem fins lucrativos, reconhecida como de utilidade pública nos âmbitos federal, estadual e municipal, dedicada à avaliação de competências cognitivas e profissionais e à pesquisa na área de educação. Por sua vez, a Fundação Ford é uma organização privada, sem fins lucrativos, criada nos Estados Unidos para ser uma fonte de apoio a pessoas e instituições inovadoras em todo o mundo, comprometidas com a consolidação da democracia, a redução da pobreza e da injustiça social e com o desenvolvimento humano.

Os organizadores desta obra têm pesquisas que enfatizam a importância de políticas públicas educacionais para enfrentamento de todas as formas de discriminação, e para a superação das desigualdades de gênero, raça, etnia e por orientação sexual; bem como em estudos que priorizam as análises quantitativas na temática das relações étnico-raciais e de gênero, além de e estudos que abarcam relações raciais e diáspora africana. As reflexões empreendidas pelos autores, homens e mulheres desse livro, é um registro do processo de implantação de uma ação específica, isto é a formação pré-acadêmica, seus resultados e as barreiras e apoios encontrados da realidade de cada instituição.

Na contemporaneidade, apontam-se as políticas de ação afirmativa como uma das estratégias, mas não a única, de combate ao racismo e à desigualdade racial brasileira. De fato, desde a década de 1980, esse tema vem sendo discutido na sociedade brasileira. Contudo, em 2000 as iniciativas ganharam destaque, proliferando no âmbito das três esferas de governo, bem como, de forma autônoma, em instituições públicas como as universidades.

Vale lembrar que desde a administração de Fernando Henrique Cardoso, passando pelos governos do Presidente Luiz Inácio Lula da Silva, e da Presidente Dilma Rousseff, o tema do racismo brasileiro tem estado nas pautas política e acadêmica brasileiras. Por meio de pressões dos movimentos sociais brasileiros, em particular do Movimento Negro, que as políticas de ação afirmativa começaram a ser introduzidas nas universidades públicas no Brasil. Observa-se, ainda o desenvolvimento de programas de valorização da cultura e da história negra e a obrigatoriedade da educação das relações étnico-raciais e do ensino de História e Cultura Afro-Brasileira e Indígena, em toda a educação básica, como resultado do reconhecimento da discriminação racial e 
do racismo como constitutivos de nossa formação social.

No Brasil, após uma década de discussão sobre a necessidade de inclusão da população negra no ensino público superior brasileiro, em 29 de agosto de 2012, a presidenta Dilma Rousseff sancionou a Lei no 12.711(Brasil, 2011) ampliando novas possibilidades quanto à inclusão nesse grau de ensino para grupos sociais historicamente dele excluídos. A lei dispõe sobre o ingresso de estudantes nas universidades federais e nos institutos federais de educação, ciência e tecnologia.

A partir da denúncia do mito da democracia, especialmente na década de 1970, o país testemunhou uma ampla mobilização em torno da questão racial, com destaque às diversas entidades do Movimento Negro, trazendo o tema de volta à arena política, fazendo com que os governantes que até então não tinham demonstrado atenção, se atentassem aos problemas das desigualdades raciais. Ao longo das últimas décadas, o Estado brasileiro tem adotado medidas que visam superar as desigualdades raciais, dando maior ênfase àquelas que dizem respeito às políticas educacionais.

Essas políticas de ação afirmativa foram criadas com o objetivo de corrigir desigualdades ou injustiças históricas, isto é, para ampliar as potencialidades da população negra do país, visando uma melhor e bem-sucedida trajetória de vida e educacional, garantida por políticas públicas localizadas, orientadas pelo princípio da equidade racial. Assim, entende-se que a implementação de ações afirmativas é justificável diante da exclusão persistente de determinados segmentos da sociedade, especialmente, os negros. Entre os objetivos das políticas de ação afirmativa, merecem destaque: alcançar maior diversidade e representatividade dos grupos ou categorias que têm sido historicamente excluídos dos espaços sociais mais valorizados; eliminar as barreiras invisíveis que dificultam o avanço social desses grupos ou categorias.

Vale lembrar que a primeira iniciativa de ação afirmativa em programas de Pósgraduação no Brasil, O Programa Internacional de Bolsas da Fundação Ford foi lançado em 2001 e contribuiu para a formação de pesquisadores/as negros/as, e/ou indígenas, muitos desses hoje inseridos em instituições de ensino superior no país.

Diante deste contexto, o livro em questão é composto de 10 capítulos, além de uma apresentação que faz um retrospecto sobre a temática de políticas de ação afirmativa no Brasil, bem como seus programas. No capítulo 1, Equidade no acesso à PósGraduação: avaliação de experiências de formação pré-acadêmica, Oliveira e Silva 
(2016) apresentam dados e reflexões originários da avaliação da implementação e da execução dos programas de formação pré-acadêmicas no que se refere ao Concurso de Dotações para a formação pré-acadêmica: Equidade na Pós-graduação pareceria entre Fundação Ford e do Departamento de Pesquisas Educacionais da FCC. Os autores apreenderam com o estudo que houve ganhos quantitativos, qualitativos e políticos no que tange ao fazer avançar uma agenda de políticas afirmativas na educação brasileira.

No capítulo 2, Afirmação na Pós-graduação: experiências, tensões, articulações e deslocamentos de uma proposta de ações afirmativas na Pós-graduação em Minas Gerais, Miranda et al.(2016) descrevem a experiência do consórcio estabelecido entre a Universidade Federal e a Estadual de Minas Gerais. Os autores no estudo observaram que se de um lado, a proposta não atingiu a população indígena, como pretendida, além da população negra, de outro lado, o curso atendeu a um grupo que não teve oportunidade de participar de projetos de iniciação científica, que na grande maioria eram egressos de instituições de ensino particulares. Os autores reforçam a importância de ações que não se limitem às ofertas de cotas, mas que considerem a relevância das condições de acesso a uma Pós-graduação, que exige entre outros: letramento acadêmico, cultura de pesquisa.

No capítulo 3, O Programa Equidade na Pós-Graduação no âmbito da Universidade Federal de Sergipe: quando a máquina burocrática trava o que salva é a força de vontade, Neves et al.(2016), chamam a atenção à provocação que as ações afirmativas despertam sobre como é definido as desigualdades na contemporaneidade e os grupos sub-representados (negros, indígenas), por elas atingidos, provocando reações contrárias, sobretudo, que se trata do âmbito da Pós-graduação. Os autores também apontam outro aspecto importante para reflexão sobre os desafios das ações afirmativas, o racismo institucional, que muitas vezes é expresso em atitudes veladas, por meio de dificuldades burocráticas e sem justificativas.

No capítulo 4, Ação afirmativa na UEMS-UCDB com vistas à equidade na PósGraduação para negros/as e indígena, Landa e Ferreira (2016) enfatizam a experiência que ambas as instituições (Universidade Estadual do Mato Grosso do Sul e Universidade Católica Dom Bosco) têm como programas específicos para as populações indígenas. Isto é, os autores chamam a atenção para aspectos determinantes que precisam ser considerados pelas ações afirmativas quando se trata das populações indígenas, 
como por exemplo, os critérios de seleção para o ingresso na Pós-graduação tem como padrão, o conhecimento de uma língua estrangeira, além do quesito do perfil etário dos grupos de indígenas que ingressam. Para os autores o grupo de indígenas ingressam mais tardiamente nos cursos de graduação, o que pode impactar a autoestima e as condições familiares na tomada de decisão para avançar numa carreira acadêmica.

O capitulo 5, Práticas de ação afirmativa: o consórcio Equidade no Centro-Oeste brasileiro, Vieira et al.(2016) dão ênfase as limitações enfrentadas na trajetória educacional pelos jovens indígenas para concluir seus estudos, apesar das políticas de incentivo. Para os autores, as políticas de cotas têm contribuído para a garantia de direito à educação de povos indígenas, porem esse direito não se pode limitar ao acesso, é necessário considerar também os meios de permanência e de modos de produção de conhecimento que considere à diversidade cultural.

No capítulo 6, Caminhos trilhados pelo Projeto Equidade na UFRB: aprendizagens e desafios, Oliveira e Ribeiro (2016) assinalam que boa parte dos estudantes que buscaram o curso de pré-formação já haviam constituído família e tinha algum tipo de vínculo empregatício, dificultando o ingresso e a permanência na Pós-graduação, somado a pequena oferta de programas de Pós-graduação na região investigada.

O capitulo 7, Eu sou porque nós somos: experiência pedagógica na articulação da equidade étnico-racial e da educação popular, Araújo-Oliveira e Montrone (2016) apresentam reflexões devido a implementação do módulo Metodologia de pesquisa e elaboração de projeto no curso Equidade no Acesso à Pós-graduação, desenvolvido na Universidade Federal de São Carlos (UFSCar), com base em vários aspectos ( aprendizagens, ensinamentos, fragilidades, dificuldades) entre outros, de natureza prática de epistemológica desveladas na execução dessa experiência pedagógica.

No capítulo 8, Formação pré-acadêmica: afirmação na Pós-Graduação, Silva e Cunha (2016) chamam a atenção para a presença de pessoas brancas entre os participantes do curso, a maioria mulheres. Nesta direção, o capítulo 9, Histórias de vida e formação pré-acadêmcia no NUREGS/UEPG, Jovino (2016), também dá ênfase a uma maioria de mulheres brancas, professoras da rede básica de educação na composição do grupo selecionado. Vale ressaltar que apesar do enfoque do edital ter sido a população negra e indígena foi necessário considerar o perfil racial da população local e considerar a demanda de gênero. 
Por fim, o capítulo 10, Ações afirmativas na Pós-Graduação: em busca da equidade social e de um projeto decolonial contra-hegemônico, Bernardino-Costa et al. (2016) estimula os leitores a refletir sobre a desestabilização de uma política hegemônica de produção de conhecimento e provoca ao alargamento de horizontes da metas das ações afirmativas para além do campo das humanidades.

Contudo, os organizadores do estudo asseguram que houve um consenso de todos os projetos aprovados pelo Programa Equidade e assinalam que ações afirmativas representam a possibilidade da população negra (pretos e/ou pardos) e indígenas ocuparem espaço na Pós- graduação no Brasil, entendido como locus de prestigio e de produção de um conhecimento social e político relevante para o desenvolvimento do país.

Vase ressaltar que o Censo de 2010 é o primeiro em que o número de pessoas autodeclaradas negras supera a população branca. Este é um fato importante também, porque reflete no ingresso de negros à educação superior e sugere uma mobilidade educacional atualmente provocada em parte pelas políticas de ação afirmativa com recorte racial na graduação. É como se houvesse uma demanda reprimida de acesso dos negros à educação superior. No passado, várias pesquisas mostravam os entraves para o negro chegar à graduação, hoje já se discute a mobilidade educacional do negro na pós-graduação, tais mudanças devem ser avalizadas no contexto das políticas de ação afirmativa.

Os estudos apresentados vêm reforçar a necessidade de implementação de políticas de ação afirmativas para a população negra (educação e mercado de trabalho). Políticas essas que, em médio prazo, possam garantir uma maior equidade de oportunidades e de padrão de vida, alterando a situação de desigualdade, e possibilitando a inclusão da população negra nos segmentos mais dinâmicos do sistema educacional e de maior renda no mercado de trabalho.

\section{Referências bibliográficas}

ARAUJO-OLIVEIRA, S; MONTRONE, A.V.G. Eu sou porque nós somos: experiência pedagógica étnico-racial e da educação popular. In: ARTES, A.; UNBEHAUM, S.; SILVÉRIO, V. (orgs.). Ações Afirmativas no Brasil: experiências bem-sucedidas de acesso na pósgraduação. São Paulo: Cortez: Fundação Carlos Chagas, p. 179- 218, 2016, v.1. 
ARTES, A.; UNBEHAUM, S.; SILVÉRIO, V.(Orgs.). Ações Afirmativas no Brasil: experiências bem-sucedidas de acesso na pós-graduação. São Paulo: Cortez: Fundação Carlos Chagas, 2016, v.1.

BERNARDINO-COSTA, J. et al. Ações afirmativas na Pós-Graduação: em busca da equidade social e de um projeto decolonial contra hegemônico. In: ARTES, A.; UNBEHAUM, S.; SILVÉRIO, V. (orgs.). Ações Afirmativas no Brasil: experiências bem-sucedidas de acesso na pós-graduação. São Paulo: Cortez: Fundação Carlos Chagas, p. 259- 282, 2016, v.1.

BRASIL. Lei n 12.711, de 29 de agosto de 2012. Brasília, DF, 29 de agosto de 2012. Disponível em: <http://www.planalto.gov.br/ccivil_03/_ato2011-2014/2012/lei/l12711.ht m>. Acesso em: 28 jun. 2107.

JOVINO, I. S. Historias de vida e formação pré-acadêmica no NUREGS/UEPG. In: ARTES, A; UNBEHAUM, S.; SILVÉRIO, V. (orgs.). Ações Afirmativas no Brasil: experiências bemsucedidas de acesso na pós-graduação. São Paulo: Cortez: Fundação Carlos Chagas, p.239-257, 2016, v.1.

LANDA, B.S. FERREIRA, E.M.L. Ação afirmativa na UEMS-UCDB com vistas à equidade na Pós-Graduação para negros/as e indígenas. In: ARTES, A.; UNBEHAUM, S.; SILVÉRIO, V. (orgs.). Ações Afirmativas no Brasil: experiências bem-sucedidas de acesso na pósgraduação. São Paulo: Cortez: Fundação Carlos Chagas, p. 113-134, 2016, v.1.

MIRANDA, S. et al. Afirmação na Pós-Graduação: experiências, tensões, articulações e deslocamentos de uma proposta de ações afirmativas na Pós-graduação em Minas Gerais.In: ARTES, A.; UNBEHAUM, S.; SILVÉRIO, V. (orgs.). Ações Afirmativas no Brasil: experiências bem-sucedidas de acesso na pós-graduação. São Paulo: Cortez: Fundação Carlos Chagas, p. 61-88, 2016, v.1.

NEVES, P.S.C. et al. O Programa Equidade na Pós-Graduação no âmbito da Universidade Federal de Sergipe: quando a máquina burocrática trava," o que salva é a força de vontade. In: ARTES, A.; UNBEHAUM, S.; SILVÉRIO, V. (orgs.). Ações Afirmativas no Brasil: experiências bem-sucedidas de acesso na pós-graduação. São Paulo: Cortez: Fundação Carlos Chagas, p. 89-112, 2016, v.1.

OLIVEIRA, A.M.S.; RIBEIRO, D.A. Caminhos trilhados pelo Projeto Equidade na UFRB: aprendizagem e desafios. In: ARTES, A.; UNBEHAUM, S.; SILVÉRIO, V. (orgs.). Ações Afirmativas no Brasil: experiências bem-sucedidas de acesso na pós-graduação. São 
Paulo: Cortez: Fundação Carlos Chagas, p. 163-178, 2016, v.1.

OLIVEIRA, F.L. SILVA, G.M. Equidade no acesso à Pós-Graduação: avaliação de experiências de formação pré- acadêmica. In: ARTES, A.; UNBEHAUM, S.; SILVÉRIO, V. (orgs.). Ações Afirmativas no Brasil: experiências bem-sucedidas de acesso na pós-graduação. São Paulo: Cortez: Fundação Carlos Chagas, p. 21-60, 2016, v.1.

SILVA, P.V. B; CUNHA, J.M. Formação pré-acadêmica: afirmação na Pós-Graduação. In: ARTES, A.; UNBEHAUM, S.; SILVÉRIO, V. (orgs.). Ações Afirmativas no Brasil: experiências bem-sucedidas de acesso na pós-graduação. São Paulo: Cortez: Fundação Carlos Chagas, p. 219- 238, 2016, v.1.

VIEIRA, P.A.S.et al. Políticas de ação afirmativa: o consórcio Equidade no Centro-Oeste brasileiro. In: ARTES, A.; UNBEHAUM, S.; SILVÉRIO, V. (orgs.). Ações Afirmativas no Brasil: experiências bem-sucedidas de acesso na pós-graduação. São Paulo: Cortez: Fundação Carlos Chagas, p. 135- 162, 2016, v.1.

Resenha recebida em 28 de junho de 2017 e aprovada em 21 de agosto de 2017. 